\title{
Physical Therapists' Perceptions of the Roles of the Physical Therapist Assistant
}

Background and Purpose. This longitudinal study investigated physical therapists' perceptions of the roles of physical therapist assistants (PTAs). Methods and Subjects. In 1986, a questionnaire describing 79 physical therapy activities was distributed to a random sample $(n=400)$ of physical therapists derived from the American Physical Therapy Association (APTA) membership. In 1992, a similar questionnaire was distributed to a representative sample $(n=400)$ of physical therapists derived from the APTA membership. Response rates were $53 \%$ and $55 \%$ in 1986 and 1992, respectively. Respondents indicated whether each activity was included in the documentation describing PTA roles. Results. Results revealed considerable agreement between therapists' perceptions of PTA roles and those outlined by PTA practice guidelines, and these perceptions cbanged little over time. Discriminant analyses suggested that therapists' perceptions of PTA roles were, in general, not predicted by supervisory experience with PTAs, therapist experience, or content of entry-level professional education curricula. Concluston and Discussion. Generally, therapists' perceptions of PTA roles are consistent with published practice guidelines. Therapists' perceptions on selected activities, bowever, were incongruent with PTA practice guidelines, suggesting the potential for inefficient or inappropriate utilization of the PTA in the delivery of selected services. [Robinson AJ, McCall M, DePalma MT, et al. Physical therapists' perceptions of the roles of the physical therapist assistant. Phys Ther. 1994;74:571-582.I

Key Words: Delivery of bealth care; Physical therapist assistant; Pbysical therapy profession, professional issues; Role.

A J Robinson, PhD, PT, is Associate Professor, Department of Physical Therapy, School of Health Sciences and Human Performance, Ithaca College, Ithaca, NY 14850 (USA). Address all correspondence to Dr Robinson

M McCall, PhD, is Assistant Professor, Department of Psychology, School of Humanities and Sciences, Ithaca College.

MT DePalma, PhD, is Assistant Professor, Department of Psychology, School of Humanities and Sciences, Ithaca College

D Clayion-Krasinski, PhD, PT, was Assistant Professor, Department of Physical Therapy, School of Health Sciences and Human Performance, lthaca College, during the initial phase of this study.

$S$ Tingley is an entry-level master's degree student in Department of Physical Therapy, Ithaca College. This study was completed in partial fulfillment of the requirements for her Bachelor of Science in Clinical Science degree.

S Simoncelli, PT, is Physical Therapist, United Cerebral Palsy Association of Western New York, Children's Center, Cheektowaga, NY 14225.

L Harnish, PT, is in private practice in Hamburg, NY 14075.

Ms Simoncelli and Ms Harnish were students in the Department of Physical Therapy at lihaca College when the initial phase of this study was completed in partial fulfillment of the requirements for their Bachelor of Science in Physical Therapy degrees.

This study was approved by the Human Subjects Review Committec of Ithaca College.

This anticle was submitted March 8, 1993, and was accepted December 7, 1993.

\author{
Andrew J Robinson \\ Michael Mccall \\ Mary T DePalma \\ Debra Clayton-Krasinski \\ Shannon Tingley \\ Suzann SImoncellI \\ LIsa Marnish
}

Physical therapist assistants (PTAs) have been active support personnel in physical therapy for over 20 years. Academic programs to prepare PTAs were initiated as early as 1967 and have proliferated across the country. Currently, 124 PTA-accredited academic programs graduate approximately 1,985 PTAs annually. ${ }^{1}$ The Bureau of Labor Statistics has estimated that the demand for PTAs will rise through the year 2000 at a rate (52\%) that approaches that for new physical therapists (57\%). ${ }^{2}$ If such a projection is realized, the PTA's influence in physical therapy will continue to grow into the next century.

The rise in the number of practicing PTAs places an increasing responsibility on those physical therapists who 
supervise PTAs. Canan has stated, "Physical therapists and physical therapist assistants must function together in patient care services .... The quality of patient care services ... will depend upon understanding and adherence to judicious delegation of responsibilities."3 Physical therapists using PTAs in patient care programs need to have an understanding of the roles of the PTA that is consistent with the PTA's level of academic preparation, the duties of the PTA as outlined by American Physical Therapy Association (APTA) documents, and state regulations governing PTA practice. Discrepancies between the actual tasks assigned to PTAs and their education and clinical competencies as outlined by the APTA and professional literature could result in either ineffective or inappropriate utilization of PTAs in the provision of physical therapy services.

\section{Resources Describing the Roles of the Physlcal Theraplst Assistant}

No single document provides a clear and comprehensive specification of the PTA's roles. The APTA House of Delegates policy on the definition and utilization of PTAs (HOD 06-88-14-25) ${ }^{4}$ defines the physical therapist assistant as "a health care worker who assists the physical therapist in provision of physical therapy" and who has graduated from an accredited PTA associate degree program. This APTA policy also outlines how the PTA is to be utilized (Appendix 1).

Further insight into the role of the PTA may be gained by a review of (1) Standard VI of the Commission on Accreditation in Physical Therapy Education's (CAPTE) Accreditation Handbook5; (2) Competencies in Physical Therapy: An Analysis of Practice, ${ }^{6}$ which delineates physical therapist and PГA competencies; (3) Standards of Ethical Conduct for the Pbysical Therapist Assistant'; (4) Guide for Conduct of the Affiliate Member ${ }^{8}$; (5) the physical therapy practice act applicable to specific states in which
PTAs practice; and (6) publications in the professional literature. ${ }^{9-11}$

\section{Review of the Literature}

Although the number of practicing PTAs has grown steadily over the last two decades, few studies have been reported that address issues related to the PTA's roles in the delivery of physical therapy services. In a pilot study in the early 1970s, Gossett ${ }^{12}$ asked PTA graduates of 11 academic programs, their supervisors, and program directors to provide information regarding the adequacy of PTA academic and clinical preparation, supervisory relationships, employer utilization, and job satisfaction. The "majority" of PTAs, clinical program directors, and supervisory physical therapists stated that the PTAs were being utilized in the delivery of services "as anticipated." The physical therapists supervising PTAs and the program directors indicated that PTAs were most qualified to perform routine treatment procedures, standard exercise techniques, follow-up gait training, and treatment of less severely involved patients. Supervisors and directors responded that PTAs were least qualified to perform evaluation and testing, specialized exercises, electrical stimulation, initial gait training, and writing of progress notes. Gossett stated that the majority of the responding PTA graduates felt they were assigned tasks compatible with their preparation. No specific instrument, however, was developed, tested, or distributed to gather information in a systematic manner from each group of respondents. With respect to PTA utilization, the report presents either "randomly chosen" comments from respondents or the author's nonquantitative interpretation of the respondents' perceptions of PTA competence. Finally, as indicated by Gossett, the small sample size and the "informality of the responses" make firm conclusions regarding PTA functions premature.

In 1973, Larson and Davis ${ }^{13}$ surveyed the members of four consecutive graduating classes of St Mary's Junior College (Minneapolis, Minn) and their supervisors to collect "information about frequency and independence of performance of 111 tasks appropriate to physical therapy departments."

With respect to "on-the-job competencies," about one quarter to one third of the supervisors indicated a need for improved preparation of PTAs for four tasks (facilitation exercises, breathing exercises, mat exercises, and first aid). The PTA graduates suggested a need for increased academic preparation of PTAs in several areas including muscle reeducation, facilitation exercises, patient evaluation, drug effects, treatment planning, mat exercises, and prosthetics. The authors noted that several of the topics were recommended by PTAs for more emphasis in PTA preparation, yet these activities were not included among PTA responsibilities in the APTA guidelines applicable at that time.

Unfortunately, Larson and Davis ${ }^{13}$ did not specify the 111 tasks they deemed appropriate to physical therapy departments, and they provided no quantitative data regarding the frequency of performance, independence of performance, or adequacy of training for more than 100 of the tasks. Finally, no information was provided regarding the reliability of their survey instrument. The report, therefore, does not allow the reader to determine what specific activities PTAs were actually performing in the early 1970 s nor whether those activities were congruent with the guidelines for PTA practice in effect at that time.

Only one study in the past 20 years has examined the clinical activities of these important support personnel. Schunk and co-workers ${ }^{14}$ reported the results of a survey conducted by the Affiliate Affairs Committee of the Oregon Physical Therapy Association using a questionnaire designed to determine, among other things, PTAs' perceptions of their knowledge and utilization of 29 specific treatment procedures, the frequency of PTA participation in 19 other routine nontreatment activities, and the nature of the supervisory relationship between 
physical therapists and PTAs. In general, the percentage of PTAs indicating knowledge of the identified treatment procedures exceeded the percentage of PTAs actually utilizing the treatment approaches in practice. Only a small number of PTAs were involved in tasks that have not been explicitly identified as being within the domain of the PTA's role such as patient evaluation, discharge planning, and patient treatment without prior physical therapist evaluation. The PTAs identified poor communication, insufficient meeting frequency, and a lack of physical therapist understanding of PTA capabilities as negative aspects of the supervisory relationship. The authors concluded from the survey data that physical therapists do not utilize PTAs to their full potential in the implementation of physical therapy services and that physical therapists may not clearly understand their supervisory responsibilities in the delegation of clinical tasks to the PTA. Although these conclusions may not be completely justified due to a lack of statistical treatment of the data and a lack of physical therapist participation, the Oregon survey results provide insight into the roles of the PTA in the provision of physical therapy services in the $1990 \mathrm{~s}$

\section{Purpose}

Physical therapists are responsible for delegating tasks to PTAs that are consistent with the PTA's educational preparation and current practice guidelines. An appreciation of the concerns regarding the scope of PTA practice cannot be complete without an understanding of physical therapists' perceptions of the PTA's roles. To date, no research has been published that has investigated physical therapists' perceptions of the roles and responsibilities of the PTA and whether those perceptions are consistent with current published guidelines. ${ }^{4-11}$

Thus, the purposes of our study were to investigate physical therapists' perceptions of the roles of the PTA and to examine whether these perceptions have changed over time.
In addition, our study compared the physical therapists' perceptions of PTA roles with those identified in APTA and other resource documents ${ }^{4-11}$ in order to identify those activities that might warrant clarification in the guidelines on PTA practice. Preliminary results of the first phase of this study have been presented previously. ${ }^{15}$

\section{Method}

\section{Sample}

A questionnaire was distributed by mail for phase 1 of the study in the fall of 1986 to a random sample $(n=400)$ of physical therapists derived from the APTA membership list. A similar survey instrument was distributed by mail for phase 2 of the study in the fall of 1992 to a representative sample $(n=400)$ of physical therapists derived from the APTA membership list. The number of names selected from a state in 1992 was in proportion to the state's total membership in the APTA.

\section{Instrumentation}

\section{Content of the questionnaire.}

A questionnaire consisting of 89 items was developed. Seventy-nine of the items identified physical therapy activities. Sixty-eight of these descriptions of activities were drawn from Competencies in Pbysical Therapy: An Analysis of Practice ${ }^{6}$ Standard VI of the CAPTE's Accreditation Handbook, 5 or the APTA House of Delegates policy statement on education and utilization of the PTA. ${ }^{4}$ Eleven of the activity items were drawn from the professional literature. ${ }^{9-11}$ No attempt was made to develop an activity list encompassing all possible activities that may take place within the physical therapy setting. Rather, the intent was to include activities that were representative of several broad aspects of physical therapy practice including the performance of clinical tests and treatments, the interpretation of test results, planning of treatment programs, and other routine operational functions performed in the clinical setting. The survey instrument was reviewed for face and content validity by researchers involved in each phase of the study. Activity items were not included in the survey if consensus was not reached regarding PTA performance of the activity or if descriptions of an activity were unclear. When no reference was found that specified an activity as an appropriate PTA role, the activity was designated as inconsistent with the guidelines on PTA practice..$^{-11}$

For each of the 79 randomly ordered items, respondents were asked to indicate whether the task was included in the role of the PTA as outlined by guidelines on PTA practice. Alternatively, the respondent could mark "Do not know." The survey response options are shown in Appendix 2.

The last 10 items comprised the second segment of the instrument and were included to gather demographic information on the respondents as well as information on their familiarity with PTAs. Copies of the questionnaires used in each phase of the study are available on request.

\section{Questionnaire development.}

In order to organize the data for analysis and presentation, a group of physical therapists $(n=13)$ were asked to place each of the 79 items into one of four activity categories: evaluation, treatment implementation, treatment planning, or administration. Results indicated substantial consistency in category assignment. Ninety percent to $100 \%$ agreement on category assignment was achieved for 56 of the activities, whereas $60 \%$ to $89 \%$ consistency in categorization occurred for 17 of the items. Less than $60 \%$ agreement regarding category assignment occurred for only 6 of the activities (determine appropriate prosthesis, orthosis, or assistive device; delegate treatment task to physical therapy aide; preparation of treatment area/ patient/equipment; modify treatment techniques; conduct clinical research; and measure/adjust crutches, canes, walkers). Using this approach, activities were assigned to categories based 
on feedback provided by this sample of physical therapists.

Eleven physical therapists were then asked to complete the questionnaire on two occasions separated by 7 to 10 days. Analyses revealed that the internal reliability of the survey instrument was quite high (Cronbach's alpha=.93). Analyses also indicated substantial test-retest reliability $(r=83)$.

The results indicated that three of the four categories were adequately reliable: evaluation (Cronbach's alpha $=$ .89), treatment implementation (Cronbach's alpha $=.73$ ), and administration (Cronbach's alpha $=.85$ ). The low reliability associated with the treatment planning category (Cronbach's alpha $=.47$ ) stems largely from a lack of agreement regarding categorization of four items (preparation of treatment area/patient/equipment, modify treatment techniques, recommend solutions to architectural barriers, and determine solutions to architectural barriers).

\section{Procedure}

For each phase of the study, a cover letter requested that the questionnaire be completed and returned in the accompanying stamped, self-addressed envelope within 3 weeks of the date of mailing. Approximately 10 days after mailing the questionnaires, a follow-up postcard was sent to each therapist on the distribution list asking them to complete and return the questionnaire if they had not already done so.

\section{Data Analysis}

Responses from returned questionnaires in each phase of the study were coded by the investigators, entered into data files, and processed using SPSS-X software.* This program allowed the investigators to calculate frequency data and use discriminant analyses to assess categorical changes in response patterns over time. For each of these analyses, one canonical discriminant function was calculated and the associated Wilk's lambda, chi-square, and significance values are reported. In addition, a Bonferroni correction factor was applied to maintain the familywise error at .05 for all comparisons. Similar analyses assessed the impact on response patterns of factors such as years of practice or supervisory experience.

\section{Results}

\section{Response Rate}

In phase 1 (1986), 53\% $(n=210)$ of the 400 distributed questionnaires were completed and returned. Responses from 5 questionnaires were excluded from subsequent analyses due to insufficient data. In phase 2 (1992), $55 \%(n=221)$ of the 400 distributed questionnaires were completed and returned. All 1992 responses were usable in subsequent analyses.

\section{Characteristics of Respondents}

The data gathered on personal characteristics of respondents in each phase of the study are summarized in Table 1. The typical respondent in each phase of the study was a female physical therapist holding a bachelor's degree in physical therapy as the highest academic degree. Seventynine percent of therapists in phase 1 and $86 \%$ of therapists in phase 2 indicated that their highest academic degree was in physical therapy.

Approximately $45 \%$ of respondents in each phase described their current position as either a staff or senior physical therapist. Forty-five percent of phase 1 respondents held positions as either director or chief of physical therapy, whereas only $13 \%$ of the phase 2 participants held such a position. About one quarter of the phase 2 respondents were in private prac- tice (similar data for phase 1 were not available).

Discriminant analyses revealed that years in practice and education regarding PTA roles in entry-level curricula were significantly different between the two survey samples. More respondents in the 1992 survey indicated less than 4 years' experience and greater than 12 years' experience than in the 1986 survey. A higher percentage of the phase 2 participants had received education on PTA roles in entry-level curricula compared with the phase 1 participants. Discriminant analyses also revealed that the number of years of clinical experience predicted responses to PTA supervision (Wilk's lambda $=96, x^{2}[4]=16.57, P<.005$ ) and whether the respondents had received information on PTA roles in their entry-level curricula (Wilk's lambda $=84, \chi^{2}[4]=69.90, P<.001$ ) That is, the greater the number of years of clinical experience, the more likely therapists were to have supervised a PTA and the less likely they were to have had academic preparation on PTA roles. Although more years of clinical experience increased the likelihood of PTA supervision, it appears that recent graduates are frequently given the responsibility of PTA supervision. In this study, 56\% of those therapists with less than 4 years of practice had supervised a PTA.

\section{Responses on Physical Therapist Assistant Roles in Evaluation Activities}

The responses of survey participants to PTA evaluative procedure items $(n=24)$ are summarized in Table 2 . Discriminant analyses revealed that responses were not significantly different across the questionnaire administrations.

The first six items listed in Table 2 were determined to be tasks consistent with guidelines on PTA practice. $^{4-11}$ The remaining 18 evaluative activities were not explicitly identified as PTA roles in reference documents.4-11 Eleven of the evaluative activities (7-17) were viewed by more

*SPSS Inc, 444 N Michigan Ave, Chicago, IL 60611. 
Table 1. Information on Respondents

\begin{tabular}{|c|c|c|c|c|}
\hline \multirow[b]{2}{*}{ Characteristic } & \multicolumn{2}{|c|}{ Percentage of Respondents } & \multirow[b]{2}{*}{$x^{2}$} & \multirow[b]{2}{*}{$\boldsymbol{P}$} \\
\hline & $\begin{array}{l}1986 \text { Survey } \\
(n=205)\end{array}$ & $\begin{array}{l}1992 \text { Survey } \\
(n=221)\end{array}$ & & \\
\hline \multicolumn{5}{|l|}{ Gender } \\
\hline Female & 71.1 & 78.1 & 2.77 & $N^{a}$ \\
\hline Male & 28.9 & 21.9 & & \\
\hline \multicolumn{5}{|c|}{ Highest earned degree } \\
\hline Bachelor's & 73.9 & 73.9 & 1.86 & NS \\
\hline Master's & 26.1 & 25.2 & & \\
\hline Doctorate & 0.0 & 0.9 & & \\
\hline \multicolumn{5}{|c|}{ Years in practice } \\
\hline$<4 y$ & 5.2 & 21.3 & 13.98 & $<.007$ \\
\hline $4-6 y$ & 23.2 & 15.4 & & \\
\hline $7-9 y$ & 17.7 & 9.5 & & \\
\hline $10-12 y$ & 12.1 & 2.2 & & \\
\hline$>12 y$ & 31.8 & 39.8 & & \\
\hline \multicolumn{5}{|c|}{$\begin{array}{l}\text { Are you currently supervising or } \\
\text { have you ever directly } \\
\text { supervised the clinical } \\
\text { activities of a PTA }{ }^{b} ?\end{array}$} \\
\hline Yes & 66.8 & 75.7 & 4.16 & NS \\
\hline No & 33.2 & 24.3 & & \\
\hline \multicolumn{5}{|c|}{$\begin{array}{l}\text { In your professional education } \\
\text { program, was information on } \\
\text { role(s) of the PTA included in } \\
\text { the curriculum? }\end{array}$} \\
\hline Yes & 35.9 & 48.4 & 7.04 & $<.008$ \\
\hline No & 64.1 & 51.6 & & \\
\hline
\end{tabular}

${ }^{a}$ NS = not significant

${ }^{b} \mathrm{PTA}=$ physical therapist assistant

than $80 \%$ of therapists as inappropriate functions of the PTA. Substantial lack of agreement between guidelines describing PTA roles and participant perceptions of appropriate roles occurred for 9 of the evaluation tasks (4-6, 18-24).

Three tasks (muscle group strength testing, performance of range-ofmotion tests, and measurement of body segment length/girth) have been included in descriptions of PTA roles, yet between $25 \%$ and $69 \%$ of the physical therapists did not endorse these activities as appropriate PTA roles. In contrast, four other activities (performance of accessory joint motion tests, specific manual muscle tests, muscle tone tests, and assess- ment of activities of daily living [ADL] PTA roles, yet more than $25 \%$ of respondents perceived these to be appropriate PTA tasks.

\section{Responses on Physical Therapist Assistant Roles in Treatment Planning}

The responses of survey participants to PTA performance of treatment planning activities are summarized in Table 3. Discriminant analyses revealed that responses did not significantly differ across the two administrations.

The first 11 items listed in Table 3 were not identified in reference docu-

ments ${ }^{4-11}$ as PTA roles. Only the last 3 items in Table 3 (modify treatment techniques; recommend solutions to architectural barriers; and prepare patient, equipment, treatment area) were PTA roles consistent with published guidelines.

More than $80 \%$ of the participants indicated that seven of the treatment planning items $(1-5,13,14)$ have not been outlined as PTA roles. In contrast, more than $30 \%$ of the respondents did not recognize that four of the treatment planning activities (8-11) have not been included in the documentation of PTA roles. Between $20 \%$ and $48 \%$ of the therapists indicated that development of therapeutic exercise programs, planning postural drainage, selection of ultrasound sèttings, design of $\mathrm{ADL}$ plan of care, planning of massage techniques, and determination of solutions for architectural barriers have been specified as appropriate PTA tasks, even though these activities have not been explicitly identified as PTA roles in practice guidelines. In contrast, almost one third of therapists did not agree that PTAs may modify treatment techniques as indicated in a plan of care, even though this activity has been identified as a PTA role in practice guidelines.

\section{Responses on Physlcal Therapist Assistant Roles in Treatment Implementation Activities}

Twenty-five of the activity items included in the questionnaire described treatment implementation activities. The responses of survey participants to PTA performance of treatments during both phases of the study are summarized in Table 4. Twenty of the items listed in Table 4 were identified as PTA roles in resource documents. ${ }^{4-11}$ However, for the 5 remaining activities (sensory reeducation, perceptual training, neurodevelopmental treatment, oral sensorimotor treatment, and measure/fit compression garments), no explicit reference was found that indicated that these activities constituted accepted PTA practice. 


\begin{tabular}{|c|c|c|c|c|c|c|c|c|}
\hline \multirow[b]{3}{*}{ Actlvity } & \multicolumn{6}{|c|}{ Percentage of Responses } & \multirow[b]{3}{*}{$x^{2}$} & \multirow[b]{3}{*}{$\boldsymbol{P}$} \\
\hline & \multicolumn{3}{|c|}{1986 Survey $(n=205)$} & \multicolumn{3}{|c|}{1992 Survey $(n=221)$} & & \\
\hline & $\mathbf{Y}$ & $\mathbf{N}$ & DK & $\mathbf{Y}$ & $\mathbf{N}$ & DK & & \\
\hline 1. Detect sudden changes in physiological state ${ }^{b}$ & 91 & 7 & 2 & 94 & 5 & 1 & 2.27 & NS \\
\hline 2. Monitor vital signs ${ }^{b}$ & 96 & 3 & 2 & 98 & 1 & 1 & 2.79 & NS \\
\hline 5. Test gross muscle group strength ${ }^{b}$ & 59 & 38 & 3 & 67 & 30 & 3 & 3.20 & NS \\
\hline 6. Perform joint ROM tests ${ }^{b}$ & 35 & 63 & 2 & 31 & 68 & 1 & 1.11 & NS \\
\hline 7. Perforrn electromyography & 1 & 95 & 3 & 1 & 95 & 4 & 0.02 & NS \\
\hline 8. Administer nerve conduction velocity tests & 2 & 95 & 3 & 1 & 94 & 5 & 1.36 & NS \\
\hline 9. Perform perceptual tests & 3 & 93 & 4 & 2 & 97 & 1 & 3.96 & NS \\
\hline 13. Determine prosthetic, orthotic/assistive device & 6 & 91 & 3 & 10 & 88 & 3 & 1.94 & NS \\
\hline 14. Test sensorimotor function & 7 & 89 & 4 & 5 & 93 & 2 & 2.57 & NS \\
\hline 15. Perform postural evaluations & 9 & 86 & 5 & 8 & 90 & 2 & .4 .13 & NS \\
\hline 16. Interpret joint integrity tests & 7 & 86 & 6 & 13 & 81 & 6 & 3.81 & NS \\
\hline 17. Perform cardiac stress tests & 8 & 82 & 10 & 9 & 82 & 9 & 0.13 & NS \\
\hline 18. Interpret developmental tests & 13 & 79 & 8 & 11 & 80 & 10 & 0.65 & NS \\
\hline 19. Test accessory joint motions & 14 & 78 & 9 & 13 & 75 & 13 & 2.16 & NS \\
\hline 20. Interpret joint ROM tests & 23 & 72 & 5 & 25 & 72 & 3 & 1.48 & NS \\
\hline 21. Perforrn specific manual muscle testing & 27 & 70 & 4 & 35 & 60 & 5 & 4.17 & NS \\
\hline
\end{tabular}

"Rounded to nearest whole valid percentage; missing values were disregarded. ( $Y=$ designated physical therapist assistant role, $N=$ not designated physical therapist assistant role, $\mathrm{DK}=\mathrm{do}$ not know, $\mathrm{ROM}=$ range of motion, $\mathrm{ADL}=$ activities of daily living, $\mathrm{NS}=$ not significant.)

'Identified from reference documents as a physical therapist assistant role.

The distribution of responses for six of the treatment activity items $(17,19-21$, $23,24)$ in Table 4 were found to be significantly different between the 1986 and 1992 surveys. For each of these six items, the phrase "given a predetermined plan of care" was included in the activity description in the 1992 version of the questionnaire. This phrase was not present for these items in the questionnaire used in 1986, and comparisons of the responses may therefore be inappropriate.

For the first 13 activities listed in Table 4 , more than $90 \%$ of physical therapists agreed that these treatment activities have been included as documented roles of the PTA. In the 1992 survey responses, the majority of therapists (ranging from $81 \%$ to $95 \%$ ) believed that performance of oral sensorimotor treatment, neurodevelopmental treatment, perceptual training, and sensory reeducation stimulation have been outlined as PTA roles, a position not congruent with existing documentation of the PTA's role. Fewer therapists saw these 4 items as PTA roles in the 1986 survey compared with the 1992 survey, although the differences in response rates may be due to the differences in the description of these items discussed previously. Only half of the therapists in 1986 believed that administration of biofeedback treatments and performance of wound debridement were specified PTA roles, whereas $73 \%$ and $82 \%$, respectively, of therapists in 1992 held these positions. Although existing guidelines include the fabrication of $\mathrm{ADL}$ adaptive equipment as a PTA role, only about one half of the responding physical therapists concurred with that position. Measurement/fit of compression garments has not been described as a role for the PTA, yet only about half of the therapists recognized this position.

\section{Responses on Physical Therapist Assistant Roles in Administrative Activities}

Sixteen of the activity items described administrative roles commonly associ- 


\section{Percentage of Responses}

\begin{tabular}{llllll}
\hline 1986 Survey $(n=205)$ & & 1992 Survey $(n=221)$ \\
Y N N & Y N N & $x^{2}$ & $P$ \\
\hline
\end{tabular}

1. Design patient plan of care
2. Change physical therapy goals/treatment techniques
3. Select traction methods/settings
4. Select electrotherapy method/settings
5. Set short-/long-term goals
6. Develop therapeutic exercise program
7. Plan postural drainage positions
8. Select ultrasound method/settings
9. Design ADL plan of care
10. Plan massage method/technique
11. Determine solutions to architectural barriers
12. Modity treatment techniques ${ }^{b}$
13. Recommend solutions to architectural barriers ${ }^{b}$
14. Prepare patient, equipment, treatment area

$\begin{array}{rrrrrrrr}7 & 92 & 1 & 5 & 92 & 3 & 3.36 & \text { NS } \\ 7 & 91 & 2 & 8 & 91 & 1 & 0.37 & \text { NS } \\ 8 & 89 & 3 & 10 & 88 & 2 & 0.69 & \text { NS } \\ 9 & 88 & 3 & 16 & 81 & 3 & 5.24 & \text { NS } \\ 17 & 81 & 3 & 10 & 87 & 3 & 4.17 & \text { NS } \\ 20 & 78 & 2 & 26 & 73 & 1 & 2.41 & \text { NS } \\ 19 & 71 & 9 & 14 & 69 & 17 & 6.63 & \text { NS } \\ 31 & 67 & 3 & 32 & 65 & 3 & 0.35 & \text { NS } \\ 32 & 64 & 5 & 28 & 66 & 6 & 0.60 & \text { NS } \\ 35 & 62 & 3 & 36 & 59 & 6 & 2.61 & \text { NS } \\ 46 & 42 & 11 & 48 & 41 & 11 & 0.20 & \text { NS } \\ 68 & 29 & 3 & 72 & 26 & 3 & 0.80 & \text { NS } \\ 86 & 6 & 8 & 89 & 7 & 4 & 2.72 & \text { NS } \\ 99 & 1 & 0 & 98 & 1 & 1 & 1.05 & \text { NS } \\ & & & & & & & \end{array}$

${ }^{a}$ Rounded to the nearest whole valid percentage; missing values were disregarded. ( $\mathrm{Y}=$ designated physical therapist assistant role, $\mathrm{N}=$ not designated physical therapist assistant role, $\mathrm{DK}=\mathrm{do}$ not know, $\mathrm{ADL}=$ activities of daily living, $\mathrm{NS}=$ not significant.)

${ }^{h}$ Identified from reference documents as a physical therapist assistant role.

ated with the operation of physical therapy services. The responses of survey participants to PTA performance of this category of items are summarized in Table 5. Statistical analyses revealed that responses to 6 items (plan PTA staff development program, select capital equipment for purchase, design fiscal management program, manage physical therapy aide employment, manage PTA employment, and develop quality assurance program) differed significantly across the two administrations. For each of these 6 items, more therapists in 1992 saw these activities as desig. nated PTA roles than in 1986.

The first 4 items listed in Table 5 were determined from a review of the references ${ }^{4-11}$ to be designated tasks for PTAs. A majority of respondents $(>65 \%)$ concurred with this perspective. The remaining 12 administrative activities have not been explicitly identified as PTA roles. The percentage of physical therapists identifying administrative functions as consistent with documented guide- lines rose for 14 of the 16 administrative items between 1986 and 1992.

\section{Factors Influencing the Pattern of Responses}

In general, respondent characteristics such as years of clinical experience, supervisory experience of PTAs, or entry-level education on PTA roles did not predict the pattern of physical therapist responses for the majority of activity items. The length of clinical experience, however, did predict the therapists' perceptions of PTA roles in development of a quality assurance program (Wilk's lambda $=.96, x^{2}[4]=15.51$, $P=.032$ ); development of a clinical research project (Wilk's lambda $=96$, $\left.\chi^{2}[4]=15.50, P=.032\right)$; management of physical therapy aide recruitment, employment, and dismissal (Wilk's lambda $=.95, \chi^{2}[4]=19.78, P=.008$ ); and development of a space management program (Wilk's lamb$\left.\mathrm{da}=.95, \chi^{2}[4]=18.38, P=.008\right)$. The results suggest that the greater the length of clinical practice, the lower the tendency to designate these activities as documented PTA functions.

Previous supervisory experience of PTAs predicted the pattern of responses for PTA involvement in designing patient plan of care (Wilk's lambda $=.96, \chi^{2}[1]=17.46$, $P=.017$ ), performance of specific manual muscle tests (Wilk's lamb$\mathrm{da}=.95, \chi^{2}[1]=19.57, P=.008$ ), performance of neurodevelopmental therapy (Wilk's lambda $=.96$, $\chi^{2}[1]=16.51, P=.025$ ), and instruction of patient/family in treatmentrelated activities (Wilk's lambda $=.96$, $\chi^{2}[1]=15.56, P=.032$ ). The pattern of responses to these items suggests that physical therapists who have supervised PTAs are more likely than those who have not supervised PTAs to indicate that providing patient/family instruction and neurodevelopmental therapy are appropriate PTA functions. In contrast, previous supervisory experience appears to make therapists less likely to designate specific manual muscle testing 


\begin{tabular}{|c|c|c|c|c|c|c|c|c|}
\hline \multirow[b]{3}{*}{ Activity } & \multicolumn{6}{|c|}{ Percentage of Responses } & \multirow[b]{3}{*}{$x^{2}$} & \multirow[b]{3}{*}{$\boldsymbol{P}$} \\
\hline & \multicolumn{3}{|c|}{1986 Survey $(n=205)$} & \multicolumn{3}{|c|}{1992 Survey $(n=221)$} & & \\
\hline & $\overline{\mathbf{Y}}$ & $\mathbf{N}$ & $\overline{\text { DK }}$ & $\overline{\mathbf{Y}}$ & $\mathbf{N}$ & $\overline{D K}$ & & \\
\hline 1. Administer therapeutic heat $/$ cold $^{b}$ & 100 & 1 & 0 & 99 & 1 & 0 & 0.25 & NS \\
\hline 2. Perform therapeutic massage ${ }^{b}$ & 100 & 1 & 0 & 99 & 1 & 1 & 1.87 & NS \\
\hline 4. Measure/adjust canes/crutches ${ }^{b}$ & 97 & 3 & 0 & 97 & 2 & 1 & 2.02 & NS \\
\hline 5. Execute therapeutic exercise ${ }^{b}$ & 97 & 3 & 0 & 98 & 1 & 1 & 2.88 & NS \\
\hline 6. Administer electrotherapy ${ }^{b}$ & 95 & 5 & 0 & 97 & 2 & 1 & 3.95 & NS \\
\hline 7. Execute fine motor dexterity exercise program ${ }^{b}$ & 95 & 4 & 1 & 96 & 3 & 1 & 0.59 & NS \\
\hline 8. Respond to acute changes in physiological state $b$ & 95 & 3 & 2 & 95 & 5 & 1 & 1.15 & NS \\
\hline 12. Administer therapeutic traction ${ }^{b}$ & 93 & 4 & 3 & 95 & 4 & 1 & 1.28 & NS \\
\hline 13. Administer postural drainage ${ }^{b}$ & 92 & 3 & 5 & 92 & 4 & 4 & 0.79 & NS \\
\hline 14. Perform intermittent venous compression techniques ${ }^{b}$ & 77 & 12 & 11 & 75 & 14 & 11 & 0.45 & NS \\
\hline 15. Perform prosthetic training ${ }^{b}$ & 77 & 19 & 4 & 80 & 14 & 6 & 2.20 & NS \\
\hline 16. Instrust patient/family in treatment-related activities ${ }^{b}$ & 75 & 19 & 5 & 82 & 14 & 4 & 3.04 & NS \\
\hline 17. Perform sensory reeducation stimulation ${ }^{c}$ & 74 & 19 & 6 & 95 & 4 & 1 & 35.03 & $<.001$ \\
\hline 18. Conduct prepartum/postpartum exercise program ${ }^{b}$ & 67 & 21 & 13 & 71 & 15 & 15 & 2.38 & NS \\
\hline 19. Perform perceptual training ${ }^{c}$ & 66 & 22 & 11 & 90 & 5 & 5 & 38.21 & $<.001$ \\
\hline 20. Perform wound debridement ${ }^{b, c}$ & 57 & 35 & 7 & 82 & 14 & 4 & 32.75 & $<.001$ \\
\hline 21. Administer neurodevelopmental treatment sessions ${ }^{c}$ & 53 & 39 & 9 & 88 & 8 & 5 & 72.28 & $<.001$ \\
\hline
\end{tabular}

${ }^{a}$ Rounded to the nearest whole valid percentage; missing values were disregarded. ( $\mathrm{Y}=$ designated physical therapist assistant role, $\mathrm{N}=$ not designated physical therapist assistant role, $\mathrm{DK}=$ do not know, $\mathrm{ADL}=$ activities of daily living, NS=not significant.)

${ }^{b}$ Identified from reference documents as a physical therapist assistant role.

"Phrase "given a predetermined plan of care" present with irem on 1992 survey; absent on 1986 survey.

and designing patient plans of care as documented PTA roles.

Information provided in entry-level professional education programs predicted response patterns on only two of the activity items: administering biofeedback therapy (Wilk's lamb$\left.\mathrm{da}=.94, \mathrm{x}^{2}[1]=24.19, P=.001\right)$ and conducting clinical research (Wilk's lambda $=.96, \chi^{2}[1]=15.33, P=.042$ ). Having had information in their professional education program made therapists more likely to identify both biofeedback therapy and implementa- tion of clinical research as documented PTA functions.

\section{Discussion}

\section{Physical Theraplsts' Perceptions of Physlcal Therapist Assistant Roles: 1986 Versus 1992}

The patterns of therapist responses to the 79 activity items for 1986 and 1992 were unchanged for 68 (86\%) of the activities. Therapist perceptions of roles for the PTA did not change for any of the performance of evaluation functions nor for any of the treatment planning items. Response patterns did change significantly, however, for 6 of the treatment implementation activities. For each of these items, however, the description of the activity was modified on the 1992 survey by adding the phrase "given a predetermined plan of care." This modification may explain these observed differences.

Significantly different patterns of responses between 1986 and 1992 were also found for six of the administrative activities. Therapist responses indicated the tendency for therapists 


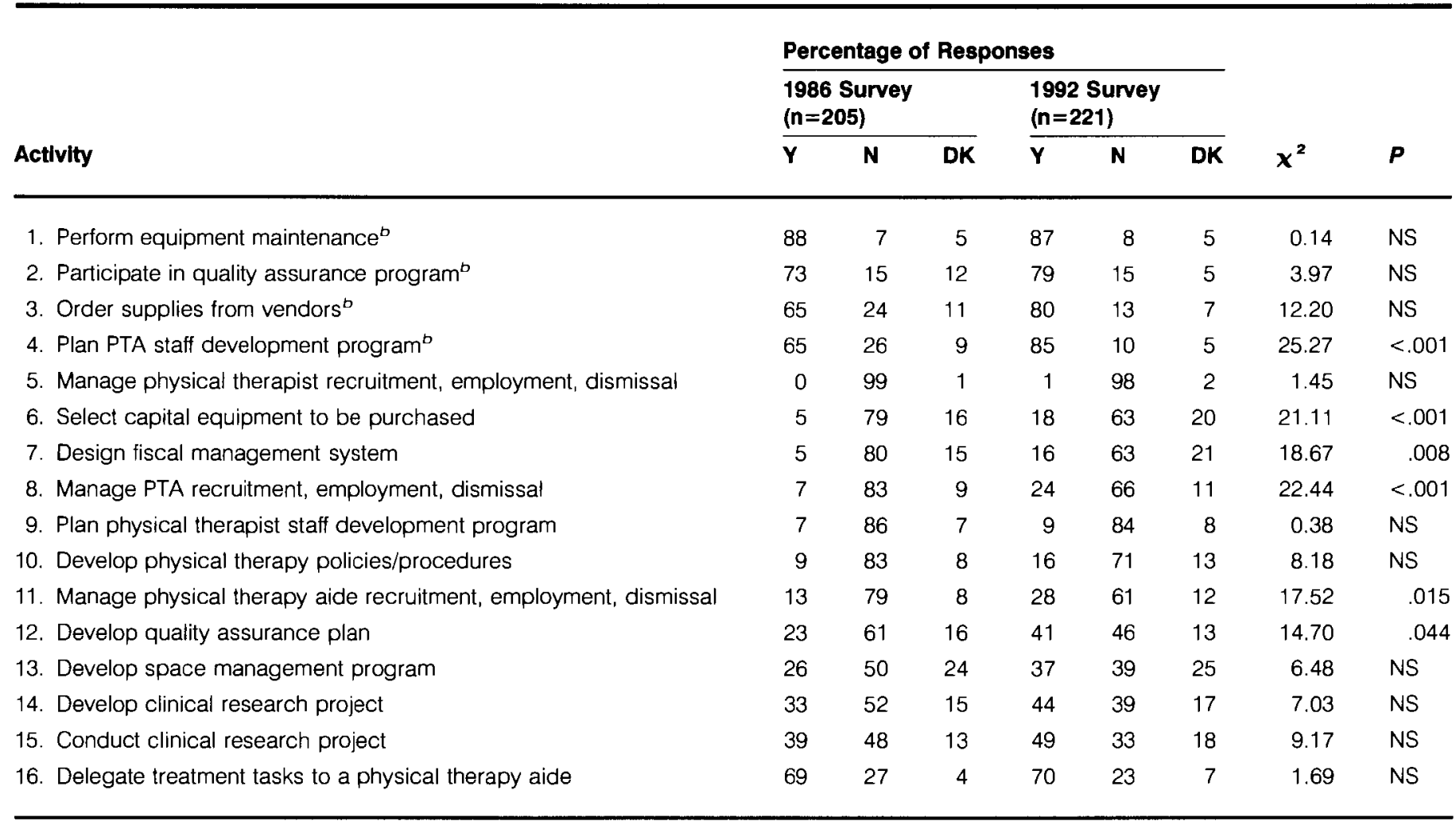

${ }^{a}$ Rounded to the nearest whole valid percentage; missing values were disregarded. (PTA=physical therapist assistant, $\mathrm{Y}=$ designated PTA role, N=not designated PTA role, DK=do not know, NS=not significant.)

${ }^{b}$ Designated by authors as a defined role of the PTA.

in 1992 to take a more expanded view of PTA involvement with these administrative activities. It is unclear at present what might account for the different pattern of responses for these six items. The number of years in practice of the therapist did predict the pattern of responses for two of these administrative activities (manage physical therapy aides, develop quality assurance program). However, as the number of years of practice increased, the less likely therapists were to designate these activities as PTA roles. It may be that PTAs have not been given the opportunity to perform these functions or that PTAs have not demonstrated to therapists their ability to satisfactorily perform these tasks.

Given that there were no major changes in APTA PTA practice guidelines ${ }^{5-7}$ and no research related to PTA roles was reported during the period between phase 1 and phase 2 , it was unclear whether therapist re- sponses would change over the period of 6 years. The policy revisions that did occur over the 6-year period were to the APTA House of Delegates policy on the definition and utilization of the PTA ${ }^{4}$ (revised 1988) and the APTA Guide for Conduct of the Affiliate Member' (amended January 1989). A few commentaries on PTA roles and responsibilities have appeared in the literature ${ }^{16}$ and press ${ }_{1}^{17-19}$ but these articles represent personal interpretations of existing APTA positions rather than sanctioned extensions of the scope of PTA practice. The only survey results reported on PTA activities ${ }^{14}$ was published following the completion of the 1992 phase of this study.

\section{Physical Therapists' Perceptions of Physical Therapist Assistant Roles in Evaluation}

Substantial disagreement with current guidelines occurred for three evalua- tive items related to musculoskeletal assessment (test gross muscle strength, perform joint ROM tests, measure length/girth of body segments), each explicitly identified as appropriate PTA evaluative activities. One potential consequence of not recognizing such activities as PTA roles is underutilization of these valuable support personnel in the clinical setting. Failure on the part of the physical therapist to have the PTA implement and report the results of basic evaluative procedures such as testing gross muscle strength and joint ROM could lead to less than optimal development or modification of patient plans of care.

For three other evaluative tasks (performance of specific manual muscle tests, assessment of muscle tone, and testing of ADL ability) not identified in the published guidelines as PTA roles, however, more than one quarter of respondents indicated that these pro- 
cedures were appropriate PTA tasks. These responses suggest the potential for overutilization of PTAs in performance of these activities. In spite of these findings, participants in this study appeared to adopt a restrictive posture in the delegation of most evaluative activities to the PTA.

\section{Physical Therapists' Perceptions of Physical Therapist Assistant Roles in Treatment Planning}

The APTA House of Delegates policy statement on the education and utilization of the PTA (HOD-06-81-13-45) indicates that the PTA function includes "performance without interpretation of selected [evaluative] procedures." The 1988 revision of this policy (HOD-06-88-14-25) states that the PTA shall not perform "identification, determination or modification of plans of care (including goals and treatment: programs)."4 Using these statements as a basis for decision making, only one activity, "recommend solutions to architectural barriers to a physical therapist," was found to be a PIA role consistent with existing guidelines.

In general, the majority of respondents agreed that treatment planning activities have not been outlined as appropriate PTA functions. Substantial numbers (between 20\% and 36\%) of physical therapists, however, believed that planning of postural drainage positions, selection of ultrasound treatment settings, design of ADL plan of care, determination of wheelchair features, and planning massage techniques have been designated as PTA roles. In addition, approximately half of the therapists thought that guidelines allow PTAs to determine solutions to architectural barriers. The pattern of responses to these six items suggests the potential for permissiveness related to the assignment of these treatment planning duties to the PTA inconsistent with APTA policy.

\section{Physical Therapists' Perceptions of Physical Therapist Assistant Roles in Treatment Implementation}

Most treatment activities have been explicitly identified in reference documents as appropriate PTA roles. A majority of physical therapist respondents agreed with this perspective. For five of the treatment activities (performance of intermittent venous compression techniques, prosthetic training, conducting prenatal/postnatal exercise programs, fabrication of adaptive equipment, and performing biofeedback treatments), more than $20 \%$ of respondents did not agree that these functions have been included in the documentation of PTA roles. Such findings suggest that physical therapists may be less inclined to delegate such treatment activities to PTAs. Thus, therapists might not make optimal use of PTAs, who are likely to have had sufficient education and training to implement these treatment tasks.

Although four of the treatment activities (sensory reeducation, perceptual training, neurodevelopmental therapy, and oral sensorimotor therapy) were not identified in reference documents as PTA roles, more than $80 \%$ of the 1992 survey physical therapist respondents believed that these clinical tasks constitute appropriate PTA functions. Such perceptions again reflect the potential for overutilization of the PTA in the provision of services.

\section{Physical Therapists' Perceptions of Physical Therapist Assistant Roles in Administration}

The most marked lack of consensus among responding therapists regarding PTA involvement in administrative functions occurred for development of clinical research, quality assurance plans, space management programs, and conducting clinical research. Such lack of consensus highlights the need for clarification of PTA involvement in administrative tasks.

An interesting finding in the administrative category was that most of the therapists indicated that documentation of the PTA's role includes delegation of treatment tasks to a physical therapy aide, an activity not explicitly identified in practice guidelines as a responsibility of the PTA. The difference of opinion on this item may stem from the interpretation of APTA policy, which states that the PTA "may carry out routine operational functions, including supervision of the physical therapy aide." 4 To date, we have been unable to determine that the operational definition of supervision includes delegation of treatment activities to a physical therapy aide.

\section{Significance of the Research}

This study has important implications for practicing physical therapists charged with the responsibility of delegating activities to PTAs. The apparent differences in therapists' perceptions of the documented role of the PTA reflects some potential for inappropriate utilization of PTAs in the clinical setting. An item-by-item review may allow the reader to focus attention on those activities for which the response rate suggests an underutilization of the education and training of the PTA. Examples in this area include the performance of joint ROM tests and the testing of gross strength of muscle groups. Discussion among physical therapists and PTAs of the activities in which the potential for underutilization of PTAs exists may lead to the formation of a consensus on the PTA's role, resulting in both the enhanced efficiency of delivery of physical therapy services and increased job satisfaction on the part of the PTA. The same item-by-item review may, however, allow therapists to recognize activities such as selection of specific modality or treatment settings and development of ADL plans of care in which PTAs may be utilized in the clinical activities in a manner inconsistent with their "defined" role. Discussions on issues related to "overutilization" of PTAs in activities not consistent with their educational preparation or outlined roles may allow supervising therapists to delegate duties congruent with the PTA's background and may avoid 
Appendix 1. American Physical Therapy Association Policy on the Utilization of the Pbysical Therapist Assistant (HOD-06-87-07-11)

The physical therapist assistant:

a. is required to work under the direction and supervision of the physical therapist.

b. may perform physical therapy procedures and related tasks that have been selected and delegated by the supervising physical therapist.

c. may carry out routine operational functions including the supervision of the physical therapy aide (or equivalent) and the documentation of treatment progress.

d. may, with the prior approval of the supervising physical therapist, adjust a specific treatment procedure in accordance with changes in patient status

The physical therapist assistant shall not perform the following:

a. interpretation of referrals.

b. physical therapy initial evaluation and reevaluation.

c. identification, determination, or modification of plans of care including goals and treatment programs.

d. final discharge assessment/evaluation or establishment of discharge plan.

e. therapeutic techniques beyond the skill and knowledge of the physical therapist assistant.

potential problems such as ineffective or unsafe delivery of patient care.

The findings of our study may provide PTAs with data on physical therapists' perceptions of the scope of PTA practice. Such information may permit PTAs to focus discussions on those areas of practice in which they seek to expand their roles. Physical therapist assistants could then provide evidence of specific entry-level preparation and continuing education to support their case for an expansion of their roles and responsibilities. Physical therapist assistants may also be surprised to note that for some of the activities included in the questionnaires, physical therapists appear to be shifting their opinion on PTA functions toward a more permissive position. Such evidence of increased per- missiveness may result from changes in the practice environment that increase demands on therapists' time (eg, physical therapist staff shortages, increased paperwork, increased patient load). Among the alternative hypotheses is that this more permissive attitude may have resulted from PTAs demonstrating competent performance of these activities.

Our findings also have important implications for academicians in physical therapy education programs. Over half of the responding physical therapists in each phase of the study indicated that no information was provided on the roles of the PTA in their professional education program. This information should stimulate those responsible for academic curricula to reexamine the manner and extent to

\section{Appendix 2. Directions and Response Key for Activity-Related Items}

For each statement below, circle the single category that best describes your opinion on the role of the physical therapist assistant. Answer:

"YES"

"NO"

"DO NOT KNOW" if, in your opinion, the task is included in the defined role of the physical therapist assistant

if, in your opinion, the task is not included in the defined role of the physical therapist assistant.

if you are not sure whether the task is included in the defined role of the physical therapist assistant. which PTA roles are addressed in their respective programs. Recent physical therapist graduates are frequently given the responsibility for supervision of PTAs and need to have a clear understanding of PTA roles in order to appropriately delegate tasks.

The final groups that should find the results of this study of interest are those responsible for defining the scope of P'TA clinical function. In reviewing the literature and documents, no single resource provided clear, comprehensive, and unambiguous information regarding PTA roles in all activities included in the questionnaire. A major concern in the implementation of this study was the lack of specificity in the designation of the PTA roles. For example, the activity "execute therapeutic exercise program given a specific plan of care" is indicated to be an appropriate PTA role in several of the major resource documents. Does this mean that PTAs are prepared to perform any activity that could broadly be defined as therapeutic exercise, ranging from programs such as progressive resistive exercise to spinal mobilization, sensory integration therapy, or work hardening? Probably not, yet the answers to such specific questions cannot be found in the currently available guidelines. ${ }^{20,21}$

\section{Suggestions for Future Research}

A number of questions need to be addressed in subsequent studies before a clear picture of contemporary PTA practice and the concerns surrounding PTA roles can be clarified. For example, what are PTAs' perceptions of their defined role, and are these perceptions congruent with those of physical therapists? What activities are physical therapists actually assigning to PTAs, and what activities do the PTAs say they are actually performing in current clinical practice? What are newly graduated physical therapists' perceptions of PTA roles? The results of studies designed to answer the first two questions could be used to identify areas of consensus on PTA roles between physical therapists and PTAs as well as 
areas that require debate and resolution in the revision of detailed PTA education and utilization guidelines. A study to address the third question could help to determine how successful physical therapist academic programs are in educating students for their role in PTA supervision.

\section{Summary}

The purpose of this study was to determine physical therapists' perceptions of the roles of the PTA over time. The results illustrated considerable agreement among therapists regarding the documented roles for the PTA. Therapist perceptions generally were consistent with documented guidelines of PTA practice. Lack of agreement among therapists and perceptions incongruent with PTA practice guidelines, however, were apparent for a number of tasks. Physical therapists' perceptions of PTA roles were not, in general, determined by the respondents' previous PTA supervision, information in entrylevel preparation on PTA roles, or the respondents' number of years of experience. In addition, therapists' perceptions of documented PTA roles changed very little over the 6-year period between the surveys. The findings indicate that academic programs educating physical therapists have not consistently provided physical therapy students with information on PTA roles in their curricula. Evi- dence that therapist perceptions on selected activities are incongruent with guidelines outlining PTA function suggests the potential for inefficient or inappropriate utilization of the PTA in the delivery of services. An important implication of this study's findings is the need for the development of clear and unambiguous guidelines detailing the scope of PTA practice.

\section{References}

1 Physical Therapist Assistant Programs. Alex andria, Va: Department of Education/Research, American Physical Therapy Association; December 1992:1-11.

2 Monthly Labor Review. Washington, DC: US Dept of Labor, Bureau of Labor; 1989:55.

3 Canan $B$. What changes are predicted for the physical therapist assistant in the 1980s? Phys Ther. 1980;60:312.

4 Definition and utilization of the physical therapist assistant. Progress Report of the American Pbysical Therapy Association. July/August 1988: 14.

5 Accreditation Handbook. Alexandria, Va: American Physical Therapy Association; 1989.

6 Competencies in Pbysical Therapy: An Analysis of Practice. 2nd ed. San Diego, Calif: Courseware Inc; 1979.

7 Standards of Ethical Conduct for the Physical Therapist Assistant. In: Minutes of the 1982 American Physical Therapy Association House of Delegates Meeting. Alexandria, Va: American Physical Therapy Association; 1982.

8 Guide for Ethical Conduct of the Affliate Member. Alexandria, Va: Judicial Committee, American Physical Therapy Association; October 1981, amended 1989.

9 Lupi-Williams FA. The PTA role and function, part 1: education. Clinical Management in Physical Therapy. 1983:3(3):35-38.
10 James $\mathrm{S}$. The PTA role and function, part 2 use of the PTA in a general practice setting-a PTA's response. Clinical Management in Pbysical Therapy. 1983;3(3):38-39.

11 Murphy P. The PTA role and function, part 3: a job description. Clinical Management in Physical Therapy. 1983;3(3):39-40.

12 Gossett RL. Assistant utilization: a pilot study. Phys Ther. 1973:53:502-506.

13 Larson CW, Davis ER. Following up the physical therapist assistant graduate: a curriculum evaluation process. Phys Ther. 1975;55 601-606.

14 Schunk C, Lippert L, Reeves B. PTA practice: in reality. Clinical Management. 1992 12(6):88-94.

15 Robinson AJ, Hanley S, Harnish L, ClaytonKrasinski D. Physical therapists' perceptions of the role of physical therapist assistants. Presented in abstract format at the annual meeting of the New York Chapter of the American Physical Therapy Association, 1986

16 Rogers JL. PTA utilization: the big picture. Clinical Management. 1991;11(4):8-9.

17 Thomas CT. Exploring the role and function of the PTA Pbysical Therapy Forum. February 7, 1992:41-42.

18 Ruddock LA. Establishing PT/PTA relationship essential to growth. Advance for Physical Therapists. April 20, 1992:7.

19 Prosanti MP. Plight of PTAs: Are skills being utilized to the fullest extent? Advance for Pbysical Therapists. March 9, 1992:8-9.

20 Evaluative Criteria for Accreditation of Education Programs for the Preparation of Pbysical Therapist Assistants Witb Interpretive Comments and Guidelines. Alexandria, Va: Commission on Accreditation in Physical Therapy Education, American Physical Therapy Association; adopted February 1993, effective July 1994.

21 Definition and Utilization of the Physical Therapist Assistant (HOD 06-93-08-09). In: Minutes of the 1993 American Physical Therapy Association House of Delegates Meeting Alexandria, Va: American Physical Therapy Association; 1993 